\title{
СЕМЕННАЯ ПРОДУКТИВНОСТЬ ВИДОВ СЕМЕЙСТВА RОSАСЕАЕ, ИСПОЛЬЗУЕМЫХ В КАЧЕСТВЕ ПОДВОЕВ В УСЛОВИЯХ ЛЕСОСТЕПИ ЗАПАДНОЙ СИБИРИ*
}

\author{
M. V. Kozlova, O. Yu. Vasilyeva, S. S. Yudanova
}

\section{SEED PRODUCTIVITY OF ROSACEAE SPECIES USED AS ROOTSTOCKS IN THE CONDITIONS OF FOREST-STEPPE OF WESTERN SIBERIA}

Козлова Маргарита Викторовна - инженер лаб. интродукции декоративных растений Центрального сибирского ботанического сада СО РАН, магистрант каф. генетики, селекции и лесоводства Новосибирского государственного аграрного университета, г. Новосибирск.

E-mail: margarita-kozlova-1996@mail.ru

Васильева Ольга Юрьевна - д-р биол. наук, зав. лаб. декоративных растений Центрального сибирского ботанического сада СО РАН, г. Новосибирск. E-mail: vasil.flowers@rambler.ru

Юданова Софья Станиславовна - канд. биол. наук, науч. сотр. Центрального сибирского ботанического сада СО РАН, г. Новосибирск.

E-mail: judanowa.sophia@yandex.ru

Цель исследования - оценить возможности получения семян подвоев для некоторых плодовых и декоративных культур в условиях лесоcmenu Западной Сибири. Рассматриваются возможности получения семенного материала Sorbus sibirica, Malus baccata u Rosa majalis 6 местах естественного произрастания, а также сбора плодов Pyrus ussuriensis $c$ деревьев, которые сформировались при отрастании побегов подвоя после гибели сортовой привойной части. Показатели потенциальной и реальной семенной продуктивности, а также коэфффиициента продуктивности имеют большое значение для оценки адаптивного потенциала видовинтродуцентов. У представителей местной фрлоры коэфффициенты семенной продуктивности используются для определения влияния гидротермических условий конкретных периодов вегетации на плодоношение. За период изучения 2017-2019 ге. коэффрициент продуктивности Rosa majalis варьировал om 67,03 до 79,11. Максимальное значение коэфффициен-
Kozlova Margarita Victorovna - Engineer, Lab. of Introduction of Ornamental Plants, Central Siberian Botanical Garden SB RAS, Magistrate Student, Chair of Selection, Genetics and Forestry, Novosibirsk State Agrarian University, Novosibirsk. E-mail: margarita-kozlova-1996@mail.ru

Vasilyeva Olga Yuryevna - Dr. Biol. Sci., Head Lab. of Ornamental Plants, Central Siberian Botanical Garden SB RAS, Novosibirsk.

E-mail: vasil.flowers@rambler.ru

Yudanova Sofya Stanislavovna - Cand. Biol. Sci., Staff Scientist, Central Siberian Botanical Garden SB RAS, Novosibirsk.

E-mail: judanowa .sophia@yandex.ru

та продуктивности вида-интродуцента Pугиs ussuriensis - 54,20, что может быть связано с ранним иветением и отсутствием достаточного числа опылителей в прохладную погоду. Выделены показатели, важные для прогнозирования количества саженцев подвоев, - масса плода и число выполненных семян в нем. Из 1 ке собранных плодов Pyrus ussuriensis можно выделить около 90 шт. выполненных семян, Sorbus sibirica - около 6500 mm., Malus baccata - около 9000 шт. Эти данные должны быть скорректированы в зависимости от полевой и лабораторной всхожести объектов (при различных методах преодоления покоя). Для изученных представителей подсемейства Maloideae характерны типы покоя $B_{2}$ или $B_{3}$, обусловленные фризиологическим механизмом торможения, для преодоления требуется длительная холодная стратификация или обработка гормонами. y Rosa majalis mun покоя комбинированный $\left(A_{2}-B_{3}\right)$ с сильным тормозящим действием околоплодника.

\footnotetext{
* Работа выполнена в рамках государственного задания Центрального сибирского ботанического сада СО РАН Проекта VI.52.1.3 «Выявление путей адаптации растений к контрастным условиям обитания на популяционном и организменном уровнях». АААA-A17-117012610053-9 (номер госрегистрации).

В экспериментах использовались материалы биоресурсной научной коллекции ЦСБС СО PAH - USU 44053 «Коллекции живых растений в открытом и закрытом грунте».
} 
Ключевые слова: подвои, Sorbus sibirica, Malus baccata, Pyrus ussuriensis, Rosa majalis, семенная продуктивность, лесостепь Западной Сибири.

The research objective was to estimate the possibilities of receiving seeds of stocks for some fruit and decorative crops in the conditions of the foreststeppe of Western Siberia. The possibilities of receiving seed material of Sorbus sibirica, Malus baccata and Rosa majalis in the places of natural growth, and also collecting the fruits of Pyrus ussuriensis from trees created at growth of rootstock shoots after the death of high-quality grafted part were considered. The indicators of potential and real seed efficiency, and also the coefficient of efficiency were of great importance for the assessment of adaptive potential of types introduced species. At representatives of local flora the coefficients of seed efficiency were used for the definition of the influence of hydrothermal conditions of the concrete periods of vegetation on fructification. During studying of 2017-2019 the coefficient of the efficiency of Rosa majalis varied from 67.03 to 79.11. The maximum value of the coefficient of efficiency of the type introduced species of Pyrus ussuriensis - 54.20 that can be connected with early blossoming and the lack of sufficient number of pollinators in cool weather. The indicators important for forecasting of quantity of saplings of stocks, the mass of the fruit and number of executed seeds in it were allocated. From $1 \mathrm{~kg}$ of collected fruits of Pyrus ussuriensis it was possible to allocate about 90 pieces of executed seeds, Sorbus sibirica about 6500 pieces, Malus baccata - about 9000 pieces. These data have to be corrected depending on field and laboratory viability of the objects ((with different methods of overcoming dormancy). Studied representatives of the Maloideae subfamily were characterized by dormant types $B_{2}$ or $B_{3}$, due to physiological mechanism of inhibition, which required long-term cold stratification or treatment with hormones. For studied representatives of the subfamily of Maloideae the types of rest of B2 or B3 caused by physiological braking mechanism were characteristic, overcoming it requires long cold stratification or processing by hormones. Rosa majalis has a combined resting type $\left(A_{2}-B_{3}\right)$ with a strong inhibitory effect of the pericarp.

Keywords: rootstocks, Sorbus sibirica, Malus baccata, Pyrus ussuriensis, Rosa majalis, seed productivity, forest-steppe of Western Siberia.
Введение. Семейство Розоцветные (Rosaceae) включает 100 родов и не менее 3000 видов растений, многие из которых имеют хозяйственную ценность в качестве пищевых, декоративных или лекарственных. Благодаря длительной селекционной работе некоторые розоцветные в качестве плодовых, ягодных или красивоцветущих культур представлены большим набором сортов, достигающим иногда десятков тысяч (например, садовые розы).

Представители всех четырех подсемейств семейства Rosaceae, имеющие хозяйственную ценность, являются модельными объектами при подготовке бакалавров, магистров и аспирантов сельскохозяйственного и ботанического направлений в рамках сотрудничества Центрального сибирского ботанического сада (ЦСБС СО РАН) с НГАУ и другими высшими учебными заведениями и НИИ Сибирского и Уральского регионов [1, 2].

Подсемейства выделяют по строению цветка и плода [3]. Для Rosoideae характерны: апокарпный гинецей из нескольких плодолистиков; пестики с одним, реже двумя семязачатками, плод - многоорешек или многокостянка. К данному подсемейству относятся ягодные растения рода Rubus (малина, ежевика и др.), Fragaria (земляника), декоративные растения рода Rosa, декоративные и одновременно лекарственные виды из родов Alchemilla, Filipendula, Geum, Potentilla.

Подсемейство Яблонные (Maloideae, или Pomoideae) характеризует синкарпный гинецей из 2-5 плодолистиков и плод яблоко. В данное подсемейство входят основные плодовые или семечковые культуры: яблоня, груша, а также рябина, айва, арония, боярышник.

Среди плодовых и декоративных культур, относящихся к родам, входящим в подсемейства Maloideae, а также Rosoideae немало таких, которые размножаются прививкой на различные виды и формы подвоев. В условиях лесостепи Западной Сибири ассортимент подвоев плодовых и особенно декоративных культур весьма ограничен, равно как и площади их маточных семенных плантаций. Нередко заготовка плодов и выделение из них семян для выращивания подвоев производится с деревьев, которые сформировались при отрастании побегов подвоя (например Pyrus ussuriensis Maxim.) после гибели сортовой привойной части. В случае, когда используемый в качестве подвоя вид яв- 
ляется представителем местной фрлоры, сбор семенного материала зачастую производится в естественных местообитаниях.

Цель исследования. Оценить возможности получения семян подвоев для некоторых плодовых и декоративных культур в условиях лесостепи Западной Сибири.

\section{Задачи исследования:}

1) оценить семенную продуктивность видов сем. Rosaceae, используемых в качестве подвоев в условиях континентального климата;

2) дать морфометрические характеристики семян некоторых видов, используемых в качестве подвоев;

3) выделить базовые характеристики плодов и семян, имеющие значение для сибирского питомниководства при заготовке семенного материала для выращивания подвоев.

Объекты, условия и методы исследования. Основными объектами исследований являлись представители подсемейства Maloideae:

- Sorbus sibirica Hedl., вид местной фрлоры, естественно произрастающий в смешанном лесу в Новосибирской области, используемый в данной зоне в качестве подвоя сортов рябины с улучшенными вкусовыми качествами [4];

- Pyrus ussuriensis, вид-интродуцент, используемый в озеленении, характеризующийся стабильным ежегодным плодоношением в условиях континентального климата лесостепи Западной Сибири, используемый в данной зоне в качестве подвоя сортов груш [5];

- Malus baccata (L.) Borkh. - считающийся видом, ушедшим из культуры и успешно натурализовавшимся в условиях лесостепи Новосибирской области, используется в данной зоне в качестве подвоя сортов яблони [4];

- а также представитель подсемейства Rosoideae - Rosa majalis Herrm., вид местной фрлоры, естественно произрастающий в подлеске смешанного леса. Используется в качестве контрольного в полевых опытах и интродукционных экспериментах по отбору устойчивых форм подвоев-шиповников различного происхождения для размножения садовых роз [4].

Объекты изучались в условиях континентального климата Новосибирска, для которого характерны умеренная обеспеченность теплом и влагой. Устойчивый снежный покров сохраняется здесь в течение 157-162 дней и достигает высоты 60-70 см. Почва промерзает на глубину 150-240 см. Безморозный период в среднем составляет 120 дней. Последние весенние заморозки отмечаются в первой декаде июня, первые осенние - во второй половине сентября. Среднегодовое количество осадков - 414 мм, из них в апреле - октябре выпадает 286 мм. Среднемесячная температура июля (самого жаркого месяца) - $18,8{ }^{\circ} \mathrm{C}$, января (самого холодного месяца) - минус $19,6^{\circ} \mathrm{C}[6,7]$.

Изучение семенной продуктивности проводилось с использованием классических методик [810] и собственных разработок, связанных с оценкой устойчивости и продуктивности подвоевшиповников [11, 12]. При изучении особенностей репродуктивной биологии шиповников под плодом подразумевался гипантий, под семенем собственно плод шиповника - орешек, так как эта терминология традиционно используется в работе с подвоями садовых роз $[13,14]$.

Морфометрические характеристики семян изучались в Центре коллективного пользования ЦСБС СО РАН С помощью стереомикроскопа Carl Zeiss Stereo Discovery V12 с цифровой камерой высокого разрешения AxioCam MRc-5 (программное обеспечение AxioVision 4.8).

Статистическая обработка полученных результатов проводилась по Б.А. Доспехову [15].

Результаты исследования и их обсуждение. При изучении семенной продуктивности Sorbus sibirica, Malus baccata и Rosa majalis плоды собирались в местах естественного произрастания, в окрестностях ЦСБС, а для получения подвоев для сортовых груш - с растений Pyrus ussuriensis, отросших после гибели привойной части.

Анализ собственных экспериментальных данных и литературных сведений $[16,17]$ показал, что для производственных (питомниководческих) целей важны данные реальной семенной продуктивности, выражающиеся в количестве выполненных семян в плоде, а также масса плода (табл.). 
Морфометрические показатели плодов и семян Pyrus ussuriensis, Sorbus sibirica, Malus baccata и Rosa majalis в лесостепи Западной Сибири

\begin{tabular}{|c|c|c|c|c|c|c|c|}
\hline \multicolumn{4}{|c|}{ Размер плода, см } & \multirow{2}{*}{\multicolumn{2}{|c|}{ Масса плода, г }} & \multirow{2}{*}{\multicolumn{2}{|c|}{$\begin{array}{l}\text { Кол-во выполненных } \\
\text { семян в плоде, шт. }\end{array}$}} \\
\hline \multicolumn{2}{|c|}{ Длина } & \multicolumn{2}{|c|}{ Ширина, диаметр } & & & & \\
\hline$X \pm s_{x}$ & $\mathrm{~V}, \%$ & $X \pm s_{x}$ & $\mathrm{~V}, \%$ & $\mathrm{X} \pm \mathrm{s}_{\mathrm{x}}$ & $\mathrm{V}, \%$ & $\mathrm{X} \pm \mathrm{s}_{\mathrm{x}}$ & $\mathrm{V}, \%$ \\
\hline \multicolumn{8}{|c|}{ Pyrus ussuriensis } \\
\hline $4,45 \pm 0,11$ & 11,36 & $5,19 \pm 0,08$ & 7,69 & $39,27 \pm 1,40$ & 16,30 & $3,55 \pm 0,20$ & 30,50 \\
\hline \multicolumn{8}{|c|}{ Sorbus sibirica } \\
\hline $11,32 \pm 0,15$ & 6,63 & $8,68 \pm 0,14$ & 8,29 & $0,46 \pm 0,01$ & 15,22 & $2,96 \pm 0,31$ & 52,03 \\
\hline \multicolumn{8}{|c|}{ Rosa majalis } \\
\hline $2,09 \pm 0,07$ & 15,79 & $1,29 \pm 0,03$ & 11,63 & $1,09 \pm 0,07$ & 31,19 & $22,56 \pm 1,22$ & 27,04 \\
\hline \multicolumn{8}{|c|}{ Malus baccata } \\
\hline- & - & $0,75 \pm 0,03$ & 21,33 & $0,68 \pm 0,04$ & 29,41 & $6,36 \pm 0,57$ & 45,13 \\
\hline
\end{tabular}

На основании этих данных было определено, что из 1 кг собранных плодов Pyrus ussuriensis можно выделить около 90 шт. выполненных семян (Sorbus sibirica - около 6500 шт., Malus baccata - около 9000 шт.).
Морфометрические характеристики семян Pyrus ussuriensis, Sorbus sibirica, Malus baccata и Rosa majalis представлены на рисунках 1-4.

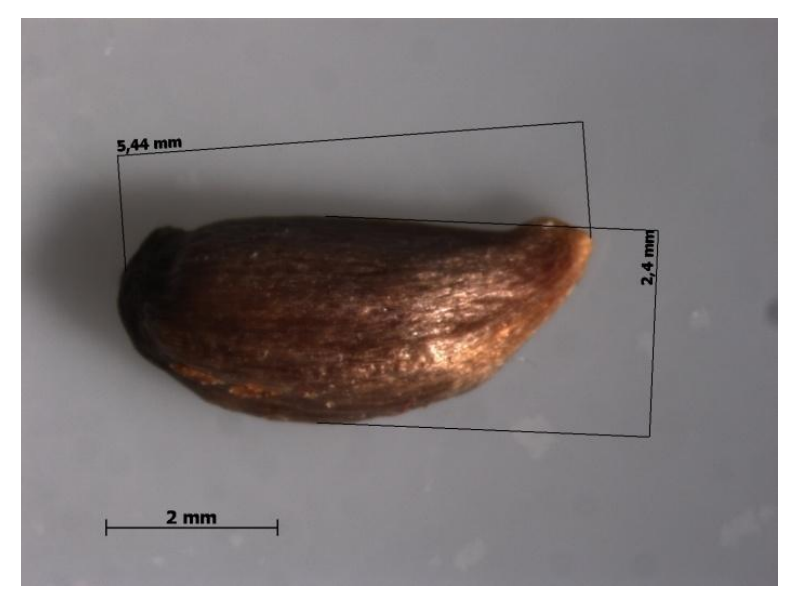

Puc. 1. Семя Malus baccata

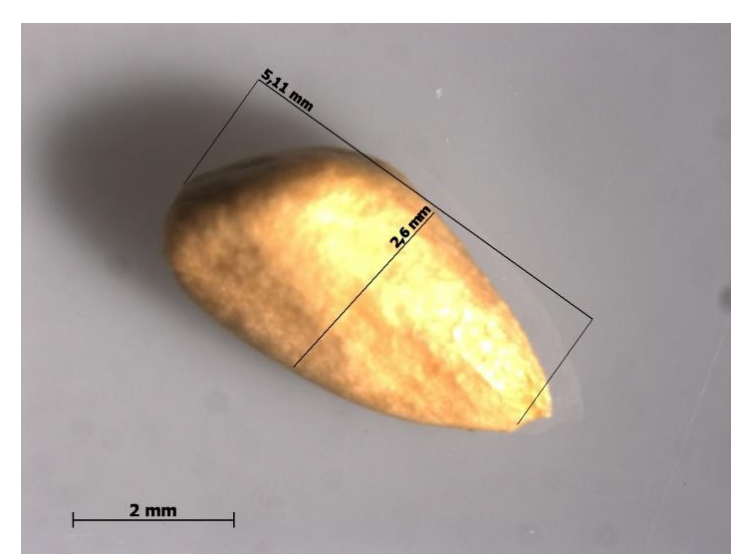

Puc. 2. Семя (плод-орешек) Rosa majalis 


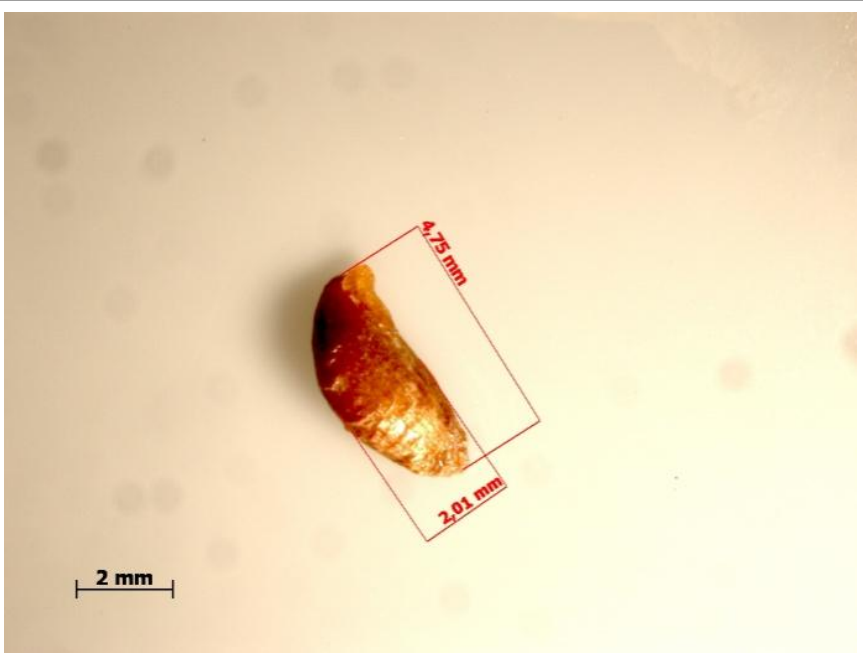

Puc. 3. Семя Sorbus sibirica

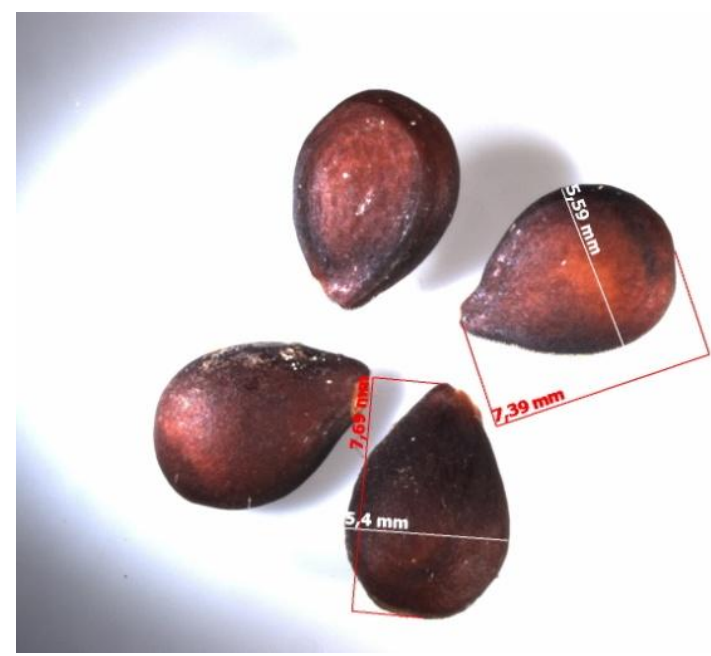

Puc. 4. Выполненные семена из одного плода Pyrus ussuriensis

Для определения потенциальной семенной продуктивности у объектов суммировалось число выполненных и невыполненных семян, а также неоплодотворенных семяпочек. Вычисленный с учетом этих параметров коэффрициент продуктивности имеет особое значение для оценки адаптивного потенциала видов-интродуцентов. Так, максимальное значение коэфффициента продуктивности Pyrus ussuriensis не превышало 54,20 , что может быть связано с ежегодным ранним цветением и отсутствием достаточного числа опылителей в прохладную погоду.

У представителей местной флоры коэффицциенты семенной продуктивности перспективно использовать для определения влияния гидротермических условий конкретных периодов вегетации на плодоношение. За период изучения
2017-2019 гг. коэфффициент продуктивности Rosa majalis варьировал от 67,03 до 79,11.

При заготовке плодов для дальнейшего выращивания саженцев подвоев должны учитываться не только масса плода и количество выполненных семян в нем, но также полевая и лабораторная всхожесть семян. Последнее усложняется тем, что для изученных представителей подсемейства Maloideae характерны типы покоя $\mathrm{B}_{2}$ или $\mathrm{B}_{3}$, обусловленные физиологическим механизмом торможения (ФМТ), для преодоления которого требуется длительная холодная стратификация или обработка гормонами $[18,19]$. У Rosa majalis тип покоя комбинированный $\left(\mathrm{A}_{2}-\mathrm{B}_{3}\right)$ с сильным тормозящим действием околоплодника, преодоление также требует холодной или тепло-холодной стратификации $[18,20]$. 
Заключение. Таким образом, в лесостепи Западной Сибири, особенно в пригородных зонах, можно найти естественно произрастающие Sorbus sibirica, Malus baccata и Rosa majalis. Для получения семян подвоев для груш можно использовать плоды Pyrus ussuriensis, сфрормировавшиеся на побегах подвоя после гибели сортовой привойной части.

Объем плодов для заготовки с целью выращивания саженцев подвоя следует определять, исходя из массы 1 плода и количества выполненных семян в нем. Учитывая тот фракт, что полевая всхожесть семян исследованных видов после холодной стратификации редко превышает $50 \%$, рекомендуется первоначально рассчитанный объем плодов увеличить в два раза.

\section{Литература}

1. Васильева О.Ю., Новикова Т.И., Воробьева И.Г. и др. Сотрудничество высшей школы и академической науки при подготовке специалистов по сохранению биоразнообразия // Самарский научный вестник. 2018. T. 7, № 2 (23). С. 233-239.

2. Васильева О.Ю., Дорогина О.В., Кубан И.Н. и др. Методические аспекты изучения биоресурсных коллекций редких и хозяйственно ценных растений // Садоводство и виноградарство. 2018. № 4 (214). C. 12-18. DOI: 10.31676/0235-2591-2018-4-12-18.

3. Еленевский А.Г., Соловьева М.П., Тихомиров В.Н. Ботаника. Систематика высших, или наземных, растений. М.: Академия, 2006. $464 \mathrm{c}$.

4. Красноборов И.М., Ломоносова М.Н., Шауло Д.Н. и др. Определитель растений Новосибирской области. Новосибирск: Наука, 2000. $492 \mathrm{c}$.

5. Чиндяева Л.Н., Томошевич М.А., Беланова А.П. и др. Древесные растения в озеленении сибирских городов. Новосибирск: ГEO, 2018. 457 c.

6. Агроклиматические ресурсы Новосибирской области. Л.: Гидрометеоиздат, 1971. $155 \mathrm{c}$.

7. Центральный сибирский ботанический сад. Новосибирск: Наука, 1981. 76 с.

8. Вайнагий И.В. О методике изучения семенной продуктивности растений // Ботанический журнал. 1974. Т. 59, № 6. С. 826-831.
9. Методические указания по семеноведению интродуцентов. М.: Наука, 1980. 63 с.

10. Международные правила определения качества семян. М.: Колос, 1969. 182 с.

11. Васильева О.Ю. Интродукция и селекция шиповников из секций Caninae Crep, Cinnamomeae DC, Indicae Thory в ЦСБС // Проблемы эволюционной цитогенетики, селекции и интродукции, Томск: ТГУ, 1996. C. $96-98$.

12. Васильева О.Ю. Биологические особенности видов рода Rosa L., интродуцируемых в качестве подвоев в Западной Сибири: дис. ... д-ра биол. наук: 03.00.05. Новосибирск, 2002. $441 \mathrm{C}$.

13. Джакипов У. Виды шиповника и возможности их использования в качестве подвоя для роз в Чуйской долине Киргизской ССР: автореф. дис. ... канд. биол. наук. Фрунзе, 1973. $21 \mathrm{c}$.

14. Сушков И.Л., Михнева Т.Н., Бессчетнова М.В. Размножение роз. Алма-Ата: Наука, 1976. $128 \mathrm{C}$.

15. Доспехов Б.А. Методика полевого опыта. М.: Агропромиздат, 1985. 350 с.

16. Иванова E.B., Сорокопудов B.H., Сорокопудова О.А. Качество плодов видов рода Malus (L.) Mill. при интродукции в условиях Белгородской области // Современные проблемы науки и образования. 2014. № 4. С. 499-505.

17. Горбунов А.Б., Симагин В.С., Фотев Ю.В. и др. Интродукция нетрадиционных плодовых, ягодных и овощных растений в Западной Сибири. Новосибирск: ГЕО, 2013. 290 с.

18. Николаева М.Г., Разумова М.В., Гладкова В.Н. Справочник по проращиванию покоящихся семян. Л.: Наука. 1985. 346 с.

19. Асбаганов С.В., Кобозева Е.В., Агафонов А.В. Покой и прорастание семян рябины сибирской в зависимости от условий хранения и обработки фитогормонами // Сибирский вестник сельскохозяйственной науки. 2016. № 5. С. 28-34.

20. Vasil'eva O.Yu. Reproduction systems of representativies of the genus Rosa L. under conditions of continental climate // Contemporary Problems of Ecology. 2009. V. 2. № 4. P. 361-368. 


\section{Literatura}

1. Vasil'eva O.Yu., Novikova T.I., Vorob'eva I.G. idr. Sotrudnichestvo vysshej shkoly i akademicheskoj nauki pri podgotovke specialistov po sohraneniju bioraznoobrazija // Samarskij nauchnyj vestnik. 2018. T. 7, № 2 (23). S. 233-239.

2. Vasil'eva O.Ju., Dorogina O.V., Kuban I.N. idr. Metodicheskie aspekty izuchenija bioresursnyh kollekcij redkih i hozjajstvenno cennyh rastenij // Sadovodstvo i vinogradarstvo. 2018. № 4 (214). S. 12-18. DOI: 10.31676/0235-2591-2018-4-12-18.

3. Elenevskij A.G., Solov'eva M.P., Tihomirov V.N. Botanika. Sistematika vysshih, ili nazemnyh, rastenij. M.: Akademija, 2006. $464 \mathrm{~s}$.

4. Krasnoborov I.M., Lomonosova M.N., Shaulo D.N. i dr. Opredelitel' rastenij Novosibirskoj oblasti. Novosibirsk: Nauka, 2000. $492 \mathrm{~s}$.

5. Chindjaeva L.N., Tomoshevich M.A., Belanova A.P. i dr. Drevesnye rastenija v ozelenenii sibirskih gorodov. Novosibirsk: GEO, 2018. $457 \mathrm{~s}$.

6. Agroklimaticheskie resursy Novosibirskoj oblasti. L.: Gidrometeoizdat, 1971. 155 s.

7. Central'nyj sibirskij botanicheskij sad. Novosibirsk: Nauka, $1981.76 \mathrm{~s}$.

8. Vajnagij I.V. O metodike izuchenija semennoj produktivnosti rastenij // Botanicheskij zhurnal. 1974. T. 59, № 6. S. 826-831.

9. Metodicheskie ukazanija po semenovedeniju introducentov. M.: Nauka, 1980. 63 s.

10. Mezhdunarodnye pravila opredelenija kachestva semjan. M.: Kolos, 1969. $182 \mathrm{~s}$.

11. Vasil'eva O.Yu. Introdukcija i selekcija shipovnikov iz sekcij Caninae Crep, Cinnamomeae DC, Indicae Thory v CSBS //
Problemy jevoljucionnoj citogenetiki, selekcii i introdukcii, Tomsk: TGU, 1996. S. 96-98.

12. Vasil'eva O.Yu. Biologicheskie osobennosti vidov roda Rosa L., introduciruemyh $v$ kachestve podvoev v Zapadnoj Sibiri: dis. ... d-ra biol. nauk: 03.00.05. Novosibirsk, 2002. $441 \mathrm{~s}$.

13. Dzhakipov U. Vidy shipovnika i vozmozhnosti in ispol'zovanija v kachestve podvoja dlja roz v Chujskoj doline Kirgizskoj SSR: avtoref. dis. ... kand. biol. nauk. Frunze, 1973. $21 \mathrm{~s}$.

14. Sushkov I.L., Mihneva T.N., Besschetnova M.V. Razmnozhenie roz. Alma-Ata: Nauka, 1976. $128 \mathrm{~s}$.

15. Dospehov B.A. Metodika polevogo opyta. M.: Agropromizdat, 1985. $350 \mathrm{~s}$.

16. Ivanova E.V., Sorokopudov V.N., Sorokopudova O.A. Kachestvo plodov vidov roda Malus (L.) Mill. pri introdukcii v uslovijah Belgorodskoj oblasti // Sovremennye problemy nauki i obrazovanija. 2014. № 4. S. 499-505.

17. Gorbunov A.B., Simagin V.S., Fotev Ju.V. i dr. Introdukcija netradicionnyh plodovyh, jagodnyh i ovoshhnyh rastenij $v$ Zapadnoj Sibiri. Novosibirsk: GEO, 2013. 290 s.

18. Nikolaeva M.G., Razumova M.V., Gladkova V.N. Spravochnik po prorashhivaniju pokojashhihsja semjan. L.: Nauka. 1985. $346 \mathrm{~s}$.

19. Asbaganov S.V., Kobozeva E.V., Agafonov A.V. Pokoj i prorastanie semjan rjabiny sibirskoj $v$ zavisimosti ot uslovij hranenija $\mathrm{i}$ obrabotki fitogormonami // Sibirskij vestnik sel'skohozjajstvennoj nauki. 2016. № 5. S. 28-34.

20. Vasil'eva O.Yu. Reproduction systems of representativies of the genus Rosa $L$. under conditions of continental climate // Contemporary Problems of Ecology. 2009. V. 2. № 4. P. 361-368. 